\title{
Dermatoethics for Dermatology Residents
}

\author{
Margaret Maria Cocks, MD, PhD
}

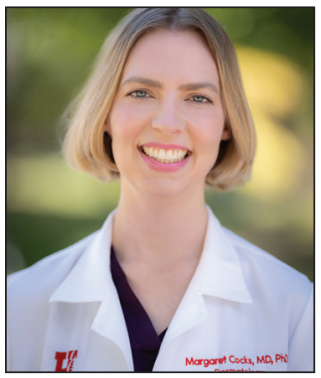

\section{RESIDENT PEARLS}

- Professionalism is one of the 6 core competencies used by the Accreditation Council for Graduate Medical Education (ACGME) to evaluate physician preparedness for autonomous practice. Dermatology residency programs are expected to provide resources for achieving this competency.

- Several resources for exploring ethical issues in dermatology are available and can be utilized to create a formal curriculum alongside the more tacit learning that takes place in daily practice.

- Learning about ethical principles and their application can ultimately help practicing physicians avoid disciplinary action and improve overall well-being.

Dermatology residents are expected to demonstrate professional behavior and an understanding of ethical principles as part of Accreditation Council for Graduate Medical Education (ACGME)accredited training programs. Incorporating this education into an already full curriculum can be challenging, but there are several dermatoethics resources available, including model curricula and textbooks that can be utilized to design custom formal curricula. This article reviews these available resources and also considers why dermatoethics training is useful in dermatology residency.

Cutis. 2021;107:E15-E17.

A s dermatology residents, we have a lot on our plates. With so many diagnoses to learn and treatments to understand, the sheer volume of knowledge we are expected to be familiar with sometimes can be overwhelming. The thought of adding yet another thing to the list of many things we already need to know-least of all a topic such as dermatoethics - may be unappealing. This article will discuss the importance of ethics training in dermatology residency as well as provide helpful resources for how this training can be achieved.

\section{Professionalism as a Core Competency}

The Accreditation Council for Graduate Medical Education (ACGME) considers professionalism as 1 of its 6 core competencies. ${ }^{1}$ These competencies provide a conceptual framework detailing the domains physicians should be proficient in before they can enter autonomous practice. When it comes to professionalism, residents are expected to demonstrate compassion, integrity, and respect for others; honesty with patients; respect for patient confidentiality and autonomy; appropriate relationships with patients; accountability to patients, society, and the profession; and a sensitivity and responsiveness to diverse patient population. ${ }^{1}$

The ACGME milestones are intended to assess resident development within the 6 competencies with more specific parameters for evaluation. ${ }^{2}$ Those pertaining to professionalism evaluate a resident's ability to demonstrate professional behavior, an understanding of ethical principles, accountability, and conscientiousness, as well as self-awareness and the ability to seek help for personal or professional well-being. The crux of the kinds of activities that constitute acquisition of these professional skills are specialty specific. The ACGME ultimately believes that having a working knowledge of professionalism and ethical principles prepares residents for practicing medicine in

From the Department of Dermatology, University of Utah School of Medicine, Salt Lake City.

The author reports no conflict of interest.

Correspondence: Margaret Maria Cocks, MD, PhD (Margaret.Cocks@hsc.utah.edu).

doi:10.12788/cutis.0286 
the real world. Because of these requirements, residency programs are expected to provide resources for residents to explore ethical problems faced by dermatologists.

\section{Beyond "Passing" Residency}

The reality is that learning about medical ethics and practicing professional behavior is not just about ticking boxes to get ACGME accreditation or to "pass" residency. The data suggest that having a strong foundation in these principles is good for overall personal well-being, job satisfaction, and patient care. Studies have shown that unprofessional behavior in medical school is correlated to disciplinary action by state licensing boards against practicing physicians. ${ }^{3,4}$ In fact, a study found that in one cohort of physicians $(\mathrm{N}=68)$, 95\% of disciplinary actions were for lapses in professionalism, which included activities such as sexual misconduct and inappropriate prescribing. ${ }^{4}$ Behaving appropriately protects your license to practice medicine.

Thinking through these problematic ethical scenarios also goes beyond coming up with the right answer. Exploring ethical conundrums is thought to develop analytical skills that can help one navigate future tricky situations that can be morally distressing and can lead to burnout. Introspection and self-awareness coupled with these skills ideally will help physicians think through sensitive and difficult situations with the courage to hold true to their convictions and ultimately uphold the professionalism of the specialty. ${ }^{5}$

Self-awareness has the additional bonus of empowering physicians to acknowledge personal and professional limitations with the goal of seeking help when it is needed before it is too late. It comes as no surprise that how we feel as physicians directly impacts how we treat our patients. One study found that depressed residents were more than 6 times more likely to make medication errors compared to nondepressed colleagues. ${ }^{6}$ Regularly taking stock of our professional and personal reserves can go a long way to improving overall well-being.

\section{Resources for Dermatoethics Training}

The best starting point for developing a robust dermatoethics curriculum is the material provided by the American Board of Dermatology, which is available online. ${ }^{7}$ An ad hoc subcommittee of the American Board of Dermatology composed of experts in dermatoethics and resident education reviewed relevant ethics literature and identified 6 core domains considered fundamental to dermatology resident education in ethics and professionalism. ${ }^{8}$ This team also provided a thorough list of relevant background readings for each topic. To cover pertinent material, the subcommittee recommended a 60-minute teaching session every other month with the intent of covering all the material over a 3-year period. If your program directors are not aware of this great resource and you feel your own ethics training may be lacking, bringing this up as a template might be helpful. A detailed description of an innovative dermatoethics curriculum organized at the Department of Dermatology at the Warren Alpert Medical School of Brown University (Providence, Rhode Island) in 2001 also may serve as a guide for programs hoping to design their own approach. ${ }^{5}$

For those interested in self-study, there is an excellent text dedicated to dermatoethics, which is aptly entitled Dermatoethics: Contemporary Ethics and Professionalism in Dermatology. ${ }^{9}$ This book offers superb case-based discussions on a wide range of ethical quandaries that dermatologists may face, ranging from unsolicited dermatologic advice (eg, Is it wrong to tell the person next to you in the grocery store that they might have a melanoma?) to research and publication ethics. This text provides a toolkit for handling tough situations in the clinic and beyond. The Journal of the American Academy of Dermatology publishes an Ethics Journal Club for which contributors can submit real-life practical ethical dilemmas, and the journal solicits a resolution or response from a dermatoethicist.

Additionally, a pilot curriculum project out of the University of Utah (Salt Lake City, Utah), of which I am a team member, currently is designing and testing several dermatoethics PowerPoint modules with the intention of making this material widely available through medical education portals.

\section{The Hidden Curriculum}

A formal curriculum can only provide so much when it comes to ethics training. In truth, much of what we learn as ethically minded dermatologists comes from our day-to-day practice. ${ }^{10}$ Paying attention to the more informal curriculum that we are immersed in during routine as well as unusual encounters also is important for achieving milestones. Teaching moments for thinking through ethical dilemmas abound, and this approach easily can be incorporated into routine workflow. ${ }^{11}$ Next time you encounter an ethical situation that gives you pause (eg, Can I biopsy an intubated patient without getting appropriate consent?), talk it through with your supervisor. Gems of autonomous practice often can be mined from these off-the-cuff conversations.

\section{Can Professionalism Be Taught?}

Finally, it is worth mentioning that while the number of resources available to dermatology residents for honing their ethics skills is increasing, ways of measuring the impact of this additional training in vivo are not. ${ }^{12}$ There are no good tools available to determine how ethics training influences resident behaviors. Similarly, there is no good evidence for what constitutes the most effective method for teaching medical ethics to trainees. It is a growing field with lots of room for more robust research. For now, the overall goal of a dermatoethics curriculum is to provide a mix of curriculum opportunities, ranging from formal lectures and readings to more informal conversations, with the hope of providing residents a toolbox for dealing with ethical dilemmas and a working knowledge of professionalism. 


\section{Final Thoughts}

There are several resources available for dermatology programs to provide quality dermatoethics training to their residents. These can be mixed and matched to create a tailored formal curriculum alongside the more informal ethics training that happens in the clinic and on the wards. Providing this education is about more than just fulfilling accreditation requirements. Understanding ethical principles and how they can be applied to navigate sensitive situations is ultimately good for both professional and personal well-being.

\section{REFERENCES}

1. Accreditation Council for Graduate Medical Education. ACGME common program requirements (residency). ACGME website. Accessed June 10, 2021. https://www.acgme.org/Portals/0/PFAssets /ProgramRequirements/CPRResidency2020.pdf

2. Edgar L, McLean S, Hogan SO, et al. The milestones guidebook. Accreditation Council for Graduate Medical Education website. Accessed June 10, 2021. acgme.org/portals/0/MilestonesGuidebook.pdf

3. Papadakis MA, Teherani A, Banach MA, et al. Disciplinary action by medical boards and prior behavior in medical school. $N$ Engl J Med. 2005;353:2673-2682
4. Papadakis MA, Hodgson CS, Teherani A, et al. Unprofessional behavior in medical school is associated with subsequent disciplinary action by a state medical board. Acad Med. 2004;79:244-249.

5. Bercovitch L, Long TP. Dermatoethics: a curriculum in bioethics and professionalism for dermatology residents at Brown Medical School. J Am Acad Dermatol. 2007;56:679-682.

6. Fahrenkopf AM, Sectish TC, Barger LK, et al. Rates of medication errors among depressed and burnt out residents: prospective cohort study. BMJ. 2008;336:488-491.

7. Recommended topics for 3-year dermatoethics curricular cycle. American Board of Dermatology website. Accessed June 10, 2021. https://www.abderm.org/residents-and-fellows/dermatoethics.aspx

8. Stoff BK, Grant-Kels JM, Brodell RT, et al. Introducing a curriculum in ethics and professionalism for dermatology residencies. J Am Acad Dermatol. 2018;78:1032-1034.

9. Bercovitch L, Perlis C, Stoff BK, et al, eds. Dermatoethics: Contemporary Ethics and Professionalism in Dermatology. 2nd ed. Springer International Publishing; 2021.

10. Hafferty FW, Franks R. The hidden curriculum, ethics teaching, and the structure of medical education. Acad Med. 1994;69:861-871.

11. Aldrich $\mathrm{N}$, Mostow E. Incorporating teaching dermatoethics in a busy outpatient clinic. J Am Acad Dermatol. 2011;65:423-424.

12. de la Garza S, Phuoc V, Throneberry S, et al. Teaching medical ethics in graduate and undergraduate medical education: a systematic review of effectiveness. Acad Psychiatry. 2017;41:520-525. 